\title{
FEATURES OF MICROFINANCING IN RUSSIA
}

\author{
Ekaterina B. Makarova \\ Russian State University for the Humanities, Moscow, Russian Federation
}

\begin{abstract}
Small business is the basis for the development of the modern economy of Russia. In modern conditions, small enterprises can be credited in various credit institutions, the most significant and popular among which are banks and microfinance organizations. The volume of the microfinance market is many times smaller than the banking one, although the number of registered microfinance organizations exceeds the number of banking credit institutions by more than 3 times. Microfinance institutions are actively developing, although in recent years, due to the economic and political situation, there has been a slowdown in their growth rates.

To date, microfinance organizations are becoming a more significant element of the financial infrastructure that supports and stimulates the growth of small and medium-sized enterprises, which in turn serves as an effective tool for combating poverty and improving the living standards of the country's population.

Microfinance in the narrow interpretation is understood only as the provision of small monetary loans (loans), and in a broader context, "microfinance" includes, in addition to direct lending, operations to attract savings, payments, insurance, leasing and a number of other financial services.

This article is devoted to the specifics of microfinance in Russia. On the basis of a comprehensive analysis of the domestic microfinance system with the systems of a developed and a developing country, namely, the USA and India, the features of providing microfinance services for small and medium businesses, as well as for nonprotected sections of the population, are revealed. The analysis of foreign experience is very important for Russia since the mechanisms of microfinance in this country are only being formed.
\end{abstract}

Key words: microfinance, microfinance institutions, microfinance services, small and medium business, population, poverty level.

УДК 339.9

ББК 65.5

\section{ОСОБЕННОСТИ МИКРОФИНАНСИРОВАНИЯ В РОССИИ}

\author{
Екатерина Борисовна Макарова \\ Российский государственный гуманитарный университет, г. Москва, Российская Федерация
}

\begin{abstract}
Аннотация. Малое предпринимательство является основой для развития современной экономики России. В настоящее время субъекты малого предпринимательства могуг кредитоваться в различных кредитных организациях, самыми значимыми и популярными среди которых являются банки и микрофинансовые организации. Объем рынка микрофинансирования во много раз меньше банковского, хотя количество зарегистрированных микрофинансовых организаций превышает количество банковских кредитных организаций более чем в 3 раза. Институты микрофинансирования активно развиваются, хотя в последнее время в связи с экономической и политической ситуацией наблюдается снижение темпов их роста.

На сегодняшний момент микрофинансовые организации становятся более значимым элементом финансовой инфраструктуры, поддерживающим и стимулирующим рост малых и средних предприятий, что в свою очередь служит действенным инструментом борьбы с бедностью и повышения уровня жизни населения страны.

Под микрофинансированием в узкой трактовке понимается только предоставление небольших денежных займов (ссуд), а в более широкой трактовке «микрофинансирование» включает в себя, кроме непосредственного кредитования, операции по привлечению сбережений, осуществление платежей, страхование, лизинг и ряд других финансовых услуг.
\end{abstract}


Данная статья посвящена особенностям микрофинансирования в России. На основании комплексного сравнительного анализа отечественной системы микрофинансирования и систем развитой и развивающейся стран, а именно - США и Индии, были выявлены особенности предоставления микрофинансовых услуг для малого и среднего бизнеса, а также для незащищенных слоев населения. Для России очень важен анализ зарубежного опыта, потому что механизмы микрофинансирования в нашей стране только формируются.

Ключевые слова: микрофинансирование, микрофинансовые институты, микрофинансовые услуги, малый и средний бизнес, население, уровень бедности.

В современных сложных и достаточно жестких условиях кредитования предприятий малого и среднего бизнеса весьма значимую роль играет микрофинансирование.

Услуги микрофинансирования в мировой практике приобрели популярность как среди представителей малого и среднего бизнеса, так и среди населения, когда денежные средства в малых количествах приобретаются для повседневной жизни (до зарплаты). Кроме того, в рамках микрофинансирования профильные организации предлагают клиентам услуги не только кредитного характера, среди которых:

- размещение средств во вклады;

- страхование;

- предоставление возможности сформировать (накопить за срок) фонд, средства из которых в будущем пойдут на оплату образования детей клиента;

- ломбардное кредитование (под залог бытовой техники, автотранспорта, меховых изделий).

Следовательно, практика свидетельствует о том, что в зарубежных странах под микрофинансированием понимается комплекс услуг для бедных слоев населения и малого бизнеса, российская практика отдает предпочтение исключительно микрокредитованию.

Необходимость наличия в стране развитой системы микрофинансирования как альтернативного источника финансирования для малого и среднего бизнеса - основы роста российской экономики весьма актуальна в настоящее время. Современные микрофинансовые организации (далее - МФО) должны обеспечить эффективное и доступное кредитование малого бизнеса, а значит, и устойчивое экономическое развитие, и повышение уровня самозанятости населения России.

Необходимо отметить, что процесс развития института микрофинансирования в России отстает от других стран в связи с отсут- ствием стратегии развития данного сектора, а также понимания его роли и места в отечественной кредитной и банковской системах. В итоге вопросы о системе микрофинансовых организаций, перечне оказываемых услуг, разграничении данных услуг с операциями коммерческих банков остаются открытыми в настоящее время.

Для выявления особенностей микрофинансирования в России был произведен сравнительный анализ институтов микрофинансирования и предоставляемых микрофинансовых услуг в России, США (как одной из ведущих стран мира с развитой экономикой) и Индии - развивающейся стране, в которой микрофинансирование достаточно широко распространено. Объектами анализа являются количество МФО, численность и структура заемщиков, объем займов, процентные ставки кредитования, объем предлагаемых услуг, а также условия микрокредитования.

Микрофинансовые институты в Индии носят не только социальный, но и политический характер, так как способствует формированию класса собственников посредством поддержки развития малого предпринимательства [1]. В экономически развитых странах (США) микрофинансовые институты в первую очередь используются в качестве эффективного инструмента для решения таких социальных задач, как снижение уровня безработицы, оказание финансовой поддержки социально неустроенным категориям гражданам за счет реализации их творческого и предпринимательского потенциала; обеспечение безболезненной интеграции в общество мигрантов и переселенцев. Достаточно успешно функционирует большое число микрофинансовых учреждений в России, использующих в своей деятельности различные методологии и технологии микрокредитования.

В США такая деятельность, как микрофинансирование, запрещена законодатель- 
ством в пятнадцати штатах. В девяти существуют строгие ограничения уровня процентной ставки - от $5 \%$ до $11 \%$ в год, а также размер займа, который не может превышать $30 \%$ от суммы заработка в месяц. В двадцати семи штатах пока остаются более либеральные законы - максимальная сумма ссуды 300-500 долл. на срок не более шести месяцев, процент не может превышать 45 \% годовых. В остальных штатах ограничений нет.

В Индии, как и в России, государство устанавливает предельные размеры начислений процентных ставок по микрокредитам МФО. В Индии процентная ставка по займам не может превышать 26 \% годовых. Если в МФО обращается группа заемщиков, то их процентная ставка равна максимум $12 \%$ в год.

С 1 января 2017 г., микрофинансовые организации в России не вправе начислять заемщику - физическому лицу проценты после того, как их сумма достигнет трехкратного размера суммы займа (данное ограничение не распространяется на неустойку (штрафы, пени), а также на платежи за услуги, оказываемые заемщику за отдельную плату). Второе ограничение касается просрочки возврата краткосрочного (до одного года) потребительского микрокредита: после возникновения просрочки МФО может начислять должнику проценты только на оставшуюся (непогашенную) часть суммы основного долга, однако начисление прекратит- ся, как только проценты достигнут двукратного размера этой суммы.

Количество МФО в США и Индии в 2015 г. находилось на одном уровне и составляло около 400 организаций, в то время как в России их почти в 9 раз больше - в Государственном реестре Центрального банка РФ на 1 января 2015 г. было зарегистрировано 3688 МФО. Однако уже к 2017 г. число МФО сократилось до 2588 (рис. 1). Связано это, прежде всего, с работой регулятора.

Несмотря на это, в России количество потребителей услуг МФО существенно меньше по сравнению с США и Индией: более чем в 4 раза и более чем в 15 раз соответственно. Меньше и доля заемщиков в общей численности населения страны: в России это $2 \%$, в США $-4 \%$, в Индии - $5 \%$, хотя разница не является такой значительной в сравнении с абсолютными показателями.

Наиболее существенны различия в структуре пользователей услугами МФО: в России это большей частью мужчины (56 \% в 2016 г.), а в США и особенно в Индии - женщины. Это обусловлено наличием специальных программ и льготных условий кредитования для женщин в США и Индии и отсутствием подобной практики в России (см. табл. 1).

Наиболее крупные займы у МФО осуществляются в Америке (10-150 тыс. долл. США), они существенно выше, чем в других странах. Средний размер займа в Индии около 100-200 долл. США, в России чуть боль-

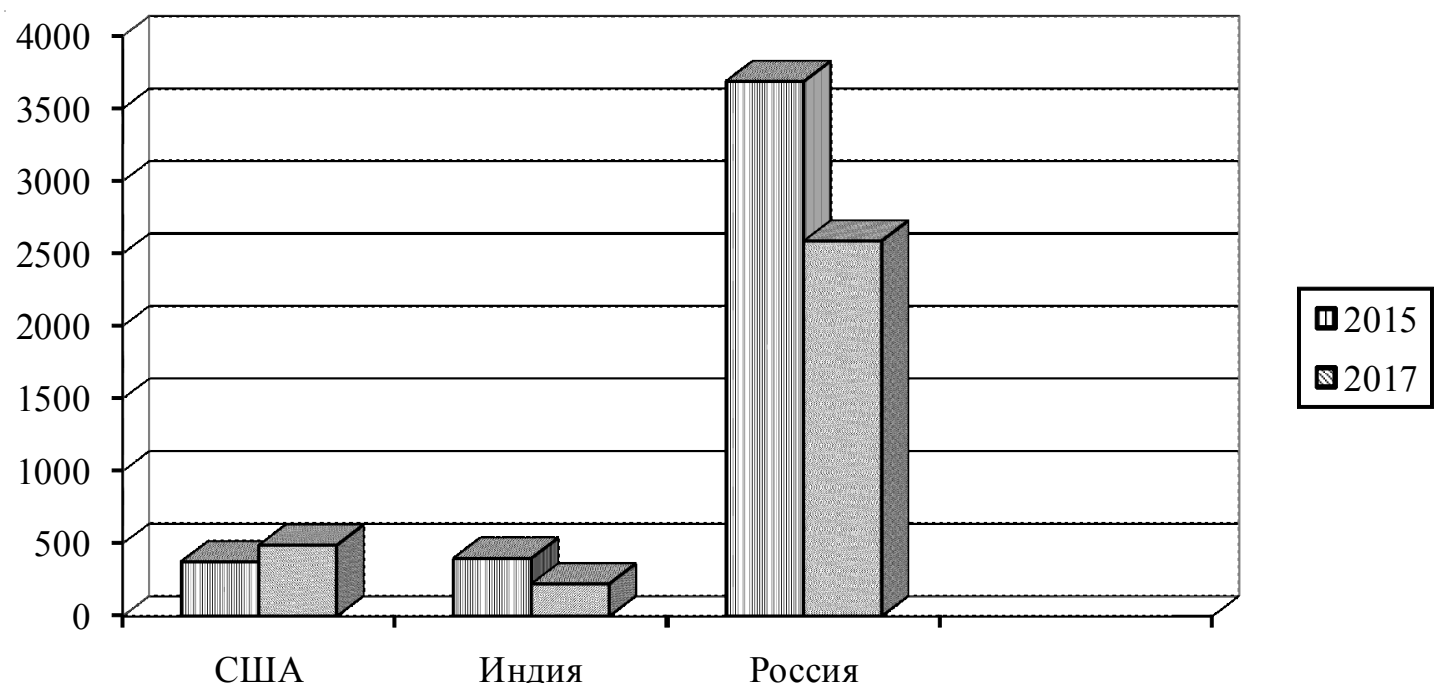

Рис. 1. Количество микрофинансовых организаций на начало 2015 и 2017 гг.

Примечание. Составлено автором по: [2; 4]. 
Количество и структура заемщиков МФО по странам в 2016 г.

\begin{tabular}{|l|c|c|c|c|}
\hline \multicolumn{1}{|c|}{ Страна } & $\begin{array}{c}\text { Количество } \\
\text { заемщиков, } \\
\text { млн чел }\end{array}$ & $\begin{array}{c}\text { Доля } \\
\text { заемщиков- } \\
\text { женщин, \% }\end{array}$ & $\begin{array}{c}\text { Доля } \\
\text { заемщиков- } \\
\text { мужчин, \% }\end{array}$ & $\begin{array}{c}\text { Темп } \\
\text { прироста } \\
\text { за год, \% }\end{array}$ \\
\hline Россия & 3,1 & 44 & 56 & $+12,5$ \\
\hline США & 13,4 & 74 & 26 & $+16,6$ \\
\hline Индия & 56,7 & 93 & 7 & $+11,2$ \\
\hline
\end{tabular}

Примечание. Составлено автором по: [2; 4].

ше - 223-744 долл. США. Такая ситуация может быть объяснена только отчасти уровнем процентных ставок, поскольку в Индии средняя ставка около $25 \%$ в год, в США от $7 \%$ до $50 \%$ в год в зависимости от штата. В России же при среднем из трех стран уровне займов средняя процентная ставка в год доходит до $700 \%$ и исчисляется в ежедневном эквиваленте от $0,5 \%$ до $2 \%$ (табл. 2).

Столь сильные различия между странами можно объяснить принципами кредитования и работы микрофинансовых организаций в целом.

Микрофинансовые институты в США это главным образом кредитные союзы (Credit Unions) [3], деятельность которых не подлежит налогообложению и лицензируется органами штата. Они представлены кооперативными кредитными учреждениями, которые организованы на принципах взаимного доверия и персональной ответственности по общим обязательствам. Большую долю составляют именно некоммерческие организации. МФО ориентированы большей частью на малый и средний бизнес, доля займов «до зарплаты» мала.

В Индии микрозаймы выдаются беднейшим слоям населения. Несмотря на то что изначально этот вид финансовых услуг задумывался как способ выдачи средств малообеспеченным людям для открытия бизнеса в условиях низкого уровня образования насе- ления, вряд ли стоит надеяться, что на небольшие суммы можно открыть успешный бизнес. Но, несмотря на это, микрозаймы все равно остаются очень полезным финансовым инструментом для жителей Индии. Ведь во многих частях этой страны население вообще не имеет доступа к банковским услугам. Благодаря МФО оно может получить средства на самые необходимые нужды под относительно невысокие проценты. Это является главной причиной столь стремительного роста индийского микрофинансового рынка.

В Индии основной массой заемщиков являются женщины и также распространено коллективное кредитование на некоммерческой основе. Такие некоммерческие МФО называются небанковскими финансовыми компаниями (NBFC). Они работают в основном в отдаленных сельских районах, тем самым обеспечивая предоставление финансовых услуг для лиц, не имеющих доступа к банковским операциям. Микрокредиты выдаются группе от 4 до 10 (максимум 20) человек под солидарную ответственность. Такие группы называются «группы взаимной ответственности» или «группы взаимопомощи».

Особенностью российского рынка микрофинансирования является большая доля потребительских микрозаймов физических лиц - более 50 \%, а краткосрочные и дорогостоящие микрозаймы «до зарплаты» составляют около 20 \% всех микрозаймов физичес-

Средний размер займа и средняя процентная ставка по странам в 2016 г.

Таблица 2

\begin{tabular}{|l|c|c|}
\hline Страна & $\begin{array}{c}\text { Средний размер займа, } \\
\text { тыс. долл. США }\end{array}$ & $\begin{array}{c}\text { Средняя процентная } \\
\text { ставка }\end{array}$ \\
\hline Россия & $0,223-0,744 *$ & $0,5-2 \%$ в день \\
\hline США & $10-150$ & $7-50 \%$ в год \\
\hline Индия & $0,100-0,200$ & $23-27 \%$ в год \\
\hline
\end{tabular}

Примечания. * - сумма среднего займа рассчитана исходя из среднего размера займа в национальной валюте Российской Федерации 15-50 тысяч рублей и курса в среднем в 2016 г. 67.19 руб. за 1 долл. США.

Составлено автором по: [2, 4]. 
ким лицам. Около 25 \% общего объема портфеля микрофинансового рынка составила доля микрозаймов, предоставленных для развития малого бизнеса (микрозаймы юридическим лицам и индивидуальным предпринимателям). Расширение объемов финансирования малого бизнеса является приоритетной задачей в развитии рынка микрофинансирования.

В России основная доля МФО является коммерческими организациями, на долю некоммерческих (региональные и муниципальные фонды поддержки предпринимательства, потребительские кооперативы финансовой взаимопомощи, кредитные кооперативы и др.) приходится не более 20 \% микрофинансового рынка. Некоммерческие МФО работают в условиях ограниченной доходности. Процентные ставки по займам некоммерческих МФО не превышают размера ключевой ставки Банка России в соответствии с требованиями федерального законодательства. Они несут социальную нагрузку, реализуют программы господдержки малого и среднего бизнеса, но при этом имеют статус МФО (рис. 2).

На рисунке 2 представлены данные по пятидесяти крупнейшим микрофинансовым организациям в каждой из сопоставляемых стран. Как видно, микрозаймы - основной вид услуг, предоставляемый всеми МФО из выборки. Такой сервис, как «микрострахование», представлен в $83 \%$ индийских компаний и всего лишь в 3 и 1 компании в США и России соответственно. Возможность размещения вклада предоставляет $30 \%$ и $20 \%$ МФО в США и Индии, в России же только одна организация из 50.

Обучение клиентов оформлению документов, составлению бизнес-планов, ведению отчетности и т. д. является обязательным продуктом для более 70 \% компаний США и Индии, в то время как в России получить данную услугу можно лишь в одной компании из $50.34 \%$ в США и $14 \%$ организаций в Индии предоставляют такую услугу, как ипотечное кредитование, а точнее микрокредит на восстановление жилья или ремонт. В России подобное направление деятельности МФО отсутствует.

Под другими услугами понимается коллективное кредитование, микролизинг, специальные программы для женщин, инвалидов, предоставление бизнес-консультаций и проведение мастер-классов. В США 38 из 50 организаций предоставляют подобные услуги, в Индии - половина. Весьма распространены в этих странах коллективное кредитование и специальные льготные программы для малоимущих групп населения. В России 34 \% организаций предоставляют другие услуги, но основную их часть составляет предоставление поручительства для получения кредита.

На основе данных проведенного анализа можно сделать ряд выводов. В рассматриваемых странах очевидны существенные различия в системах микрофинансирования. Несмотря на большое количество микрофи-

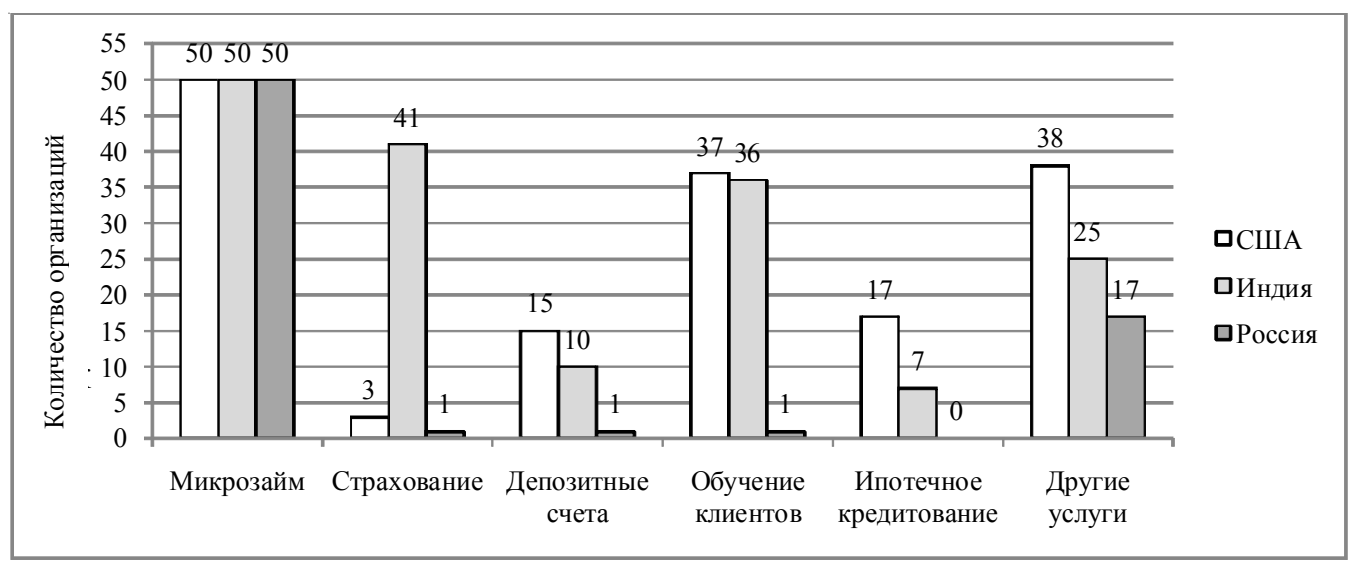

Рис. 2. Услуги, предоставляемые 50 крупнейшими микрофинансовыми организациями в США, Индии, России

Примечание. Составлено автором по публикуемой отчетности 50 крупнейших микрофинансовых организаций США, Индии и России. 
нансовых компаний в России по сравнению с другими странами, доля населения, пользующаяся данными услугами, является низкой и составляет всего $2 \%$.

МФО в России не обеспечивают необходимый уровень услуг для социально незащищенных слоев населения. Размеры займа являются также невысокими, а проценты по нему очень большими, на рынке большую долю занимает потребительское микрокредитование физических лиц. К тому же необходимо обратить внимание на количество предоставляемых услуг микрофинансовыми организациями. Если в США и Индии, обратившись в микрофинансовую организацию, можно получить такие услуги, как бизнес-обучение, консалтинг, страхование и т. д., то в России подобный сервис предоставлен лишь в одной компании из 50.

Изначально микрофинансирование было направлено на снижение уровня бедности, помощь наименее социально защищенным слоям населения, оно должно давать больше возможностей для малого бизнеса, чем банковское кредитование. Большинство МФО в Соединенных Штатах являются некоммерческими организациями, в Индии количество таких компаний составляет около половины, что в целом соответствует принципам и предназначению микрофинансовой деятельности. В России, по результатам исследования, из 50 крупнейших микрофинансовых компаний нет ни одной некоммерческой организации, то есть главной целью деятельности всех компаний является получение прибыли.

Сравнивая систему микрофинансирования России с системами других стран, можно сделать вывод о том, что она представлена лишь микрокредитованием и не выполняет своего прямого назначения, так как цель МФО в России - получение прибыли и сверхприбыли, а не помощь наименее защищенным слоям населения и малому бизнесу.

Для дальнейшего полноценного развития системы микрофинансирования и связанных с ней отраслей экономики считаем необходимым принять соответствующие меры, а именно:
- более жесткое регулирование и надзор деятельности МФО. Использование двухуровневой системы надзора позволит сократить нелегальные МФО, усилить конкуренцию, сделает рынок более прозрачным, появятся новые точки роста, а также расширятся возможности фондирования МФО;

- самим МФО необходимо повышать лояльность своих клиентов, расширять конкурентные преимущества, используя современные технологии и спектр предоставляемых услуг.

\section{СПИСОК ЛИТЕРАТУРЫ}

1. Гладкова, Е. В. Микрофинансирование как инновационный инструмент развития кредитной системы РФ : дис. ... д-ра экон. наук / Гладкова Вера Егоровна. - Москва, 2013. - 370 с.

2. Обзор ключевых показателей микрофинансовых организаций // Центральный банк Российской Федерации. - Электрон. текстовые дан. - Режим доступа: https:// www.cbr.ru/. - Загл. с экрана.

3. Паршин, В. В. Согласование экономических интересов в непроизводственной сфере : дис. ... канд. экон. наук / Паршин Виктор Викторович. Пятигорск, 2011.-173 с.

4. Microfinance Barometer - Electronic text data. - Mode of access: https://http://www.micro financegateway.org. - Title from screen.

\section{REFERENCES}

1. Gladkova E.V. Mikrofinansirovanie kak innovatsionnyy instrument razvitiya kreditnoy sistemy RF: dis. ... d-ra ekon. nauk [Microfinance as an Innovative Tool for the Development of the Credit System of the Russian Federation. Dr. econ. sci. diss.]. Moscow, 2013.370 p.

2. Obzor klyuchevykh pokazateley mikrofinansovykh organizatsiy [Overview of Key Indicators of Microfinance Organizations]. Tsentralnyy bank Rossiyskoy Federatsii [Central Bank of the Russian Federation]. URL: https: // www.cbr.ru/.

3. Parshin V.V. Soglasovanie ekonomicheskikh interesov $v$ neproizvodstvennoy sfere: dis. ... kand. ekon. nauk [Coordination of Economic Interests in the Non-Production Sphere. Cand. econ. sci. diss.]. Pyatigorsk, 2011. $173 \mathrm{p}$.

4. Microfinance Barometer. URL: http://www. microfinancegateway.org. 


\section{ФИНАНСЫ. БУХГАЛТЕРСКИЙ УЧЕТ}

\section{Information about the Author}

Ekaterina B. Makarova, Senior Lecturer, Department of Finance and Credit, Russian State University for the Humanities, Miusskaya Sq., 6, 125993 Moscow, Russian Federation, rusheva@bk.ru.

\section{Информация об авторе}

Екатерина Борисовна Макарова, старший преподаватель кафедры финансов и кредита, Российский государственный гуманитарный университет, Миусская пл., 6, 125993 г. Москва, Российская Федерация, rusheva@bk.ru. 